\title{
Conversion due to vascular injury during video-assisted thoracic surgery lobectomy: A multicentre retrospective analysis from the Italian video-assisted thoracic surgery group registry ${ }^{\text {ir }}$
}

\author{
a Department of Thoracic Surgery, Maggiore Teaching Hospital, Bologna, Italy \\ b Department of Thoracic Surgery, AUSL Romagna Hospitals, Forlì- Ravenna, Italy \\ c Division of Thoracic Surgery and Lung Transplantation, ISMETT, UPMC Italy, Palermo, Italy \\ d Department of Thoracic Surgery, Carlo Poma Hospital, Mantova, Italy \\ e Department of Thoracic Surgery, University Hospital Careggi, Florence, Italy \\ ${ }^{\mathrm{f}}$ Department of Thoracic Surgery - University of L'Aquila, Mazzini Hospital, Teramo, Italy
}

Luca Bertolaccini ${ }^{\text {a, }}{ }^{*}, 1$, Fabio Davoli ${ }^{\text {b, }}{ }^{\text {, }}$, Alessandro Pardolesi ${ }^{\text {a }}$, Jury Brandolini ${ }^{\mathrm{b}}$, Desideria Argnani ${ }^{b}$, Alessandro Bertani ${ }^{c}$, Andrea Droghetti ${ }^{d}$, Alessandro Gonfiotti ${ }^{\text {e, }}$ Duilio Divisi ${ }^{\mathrm{f}}$, Roberto Crisci ${ }^{\mathrm{f}}$, Piergiorgio Solli ${ }^{\mathrm{a}}$, Italian VATS Group

\section{A R T I C L E I N F O}

\section{Article history:}

Received 19 June 2018

Received in revised form

14 December 2018

Accepted 29 December 2018

Available online 8 January 2019

\section{Keywords:}

Lung cancer

Video-assisted thoracic surgery lobectomy

Conversion

Vascular injury

Complications

Lymph nodes dissection

\begin{abstract}
A B S T R A C T
Objectives: Vascular injuries are among the most severe causes of unplanned conversion during VATS lobectomies. The study aimed to analyse the incidence of vascular injuries and their risk factors during VATS lobectomy.

Methods: The Italian VATS lobectomy Registry was used to collect data from 66 Thoracic Surgery Units. From 2013 to October 2016 (out of more than 3,700 patients enrolled) only information from Units with an enrollment $>100$ VATS lobectomies were retrospectively analysed. Logistic regression analysis was performed on selected variables of the univariate analysis.

Results: Ten institutions contributed a total of 1,679 patients. Vascular injuries leading to conversion occurred in $44(2.6 \%)$ patients. Years of experiences were inversely related to the risk of vascular injuries. Univariate analysis showed age, gender, surgical activity, Charlson Index Score and number of resected lymph nodes like significantly associated variables. Multivariate analysis revealed that number of resected lymph nodes, VATS experience ratio (number of VATS lobectomies/total lobectomies performed in the same year at same centre), and surgical activity of the centre were significantly associated with the risk of conversion. Unplanned thoracotomy was correlated with postoperative morbidity.

Conclusion: Vascular injuries in VATS lobectomies represented a rare complication which could directly affect the postoperative outcomes. The predictive factors for conversion were multifactorial and depended on characteristics of centres and surgeons' seniority. Minimally invasive VATS lobectomy approaches did not influence the risk of vascular damages.
\end{abstract}

( 2019 Elsevier Ltd, BASO The Association for Cancer Surgery, and the European Society of Surgical Oncology. All rights reserved.

\footnotetext{
Meeting Presentation: Presented at the 25th European Conference on General Thoracic Surgery of the European Society of Thoracic Surgeons in Innsbruck (A), 28-31 May 2017.

* Corresponding author. Department of Thoracic Surgery, Maggiore Teaching Hospital, Largo Nigrisoli 2, 40133, Bologna, Italy.

E-mail address: luca.bertolaccini@gmail.com (L. Bertolaccini).

1 These authors have equally contributed to this paper.
}

\section{Introduction}

The pivotal role of Video-Assisted Thoracic Surgery (VATS) lobectomy in the management of lung cancer has been extensively explored for more than a decade. VATS lobectomy is associated with a decreased morbidity, better quality of life and a reduced hospital length of stay, while yields survival rates similar to thoracotomic lobectomy [1]. Nowadays VATS lobectomy is accepted as the standard surgical modality for early-stage not small cell lung 
cancer (NSCLC) and has been gradually applied also to more advanced stages of lung cancer. The penetrance of this technique has been somewhat slow in the last 25 years in the thoracic surgeon community, due to many reasons and including the fear of major intraoperative complications that have been proved to be rare but potentially catastrophic events [2]. Injuries to vascular structures might be uncontrollable and call for an emergency and unplanned conversion or, worse, might necessitate a major pulmonary resection. A detailed check-list of intraoperative signals that would alert surgeons to potential risk situations lacks in the current literature. Increasing the awareness of significant risk factors or near-miss situations encountered during the procedure may perhaps be one of the strategies to avoid them and to facilitate a more significant and safer adoption of the technique [3].

This study aimed to assess the incidence of vascular injuries and to identify their risk factors during VATS lobectomies through data available from the Italian VATS lobectomy Registry.

\section{Material and methods}

The Italian VATS lobectomy Registry was developed in 2013 by the Italian VATS Group with the goal of analysing the national VATS lobectomy experience. At this moment, the VATS registry has been used to prospectively collect data from 55 Italian Thoracic Surgery Units [4]. The database receives only VATS lobectomies performed without the use of a rib spreader, monitor-based procedures without a direct intrathoracic view, with separated isolation/division of the hilar structures and lymph node staging (in the case of lung cancer resections) according to the European Society of Thoracic Surgeons (ESTS) guidelines [5]. Since VATS experienced surgeons frequently engaged challenging oncological cases with a higher chance for conversion [6] and mainly to review data coming from high-volume centres, only information from Units with $>100$ VATS lobectomies enrolled were retrospectively analysed. The arbitrary cut-off was first derived from the range of the learning curve for VATS lobectomy [7,8] and adjusted according to the ESTS minimal requirements for Thoracic Surgery units [9]. According to previous literature, seniority was stratified by years of experience in the consultant position and ten years were selected as the arbitrary cutoff [6]. The data collected from Registry included multiple variables: gender, age, surgical indication (benign, primary or metastatic), previous chemotherapy or radiotherapy, Charlson Comorbidity Index [10], Eastern Cooperative Oncology Group Performance Status (ECOG PS) [11], previous surgery, side and surgical procedure performed, tumour diameter, number of incisions, number of resected lymph nodes, cause of conversion (e.g. vascular injuries, etc), final pathological stage (according to TNM VII Edition [12]), overall postoperative complications, hospital length of stay. Unfortunately, in a portion of the rough record of the "vascular injury", more information on the detailed mechanisms was not available in the current version of the Registry. The surgical activity of each participating centre, defined as the overall number of lobectomies at the time of the study, was also recorded. The VATS experience ratio was calculated as the direct ratio of the number of VATS lobectomies over the overall anatomical resections (performed in the same year at each centre) [13]. Conversions to thoracotomy for oncological or other reasons were excluded since the focus of the paper concentrated on vascular complications. Institutional Review Board approval (No. $=81 / 2014 / 0 / O s s$ ) was obtained. The data were anonymously achieved according to the International Conference on Harmonization Guidelines for Good Clinical Practice [14].

\section{Statistical analysis}

Continuous variables were reported as the mean \pm standard deviation, whereas categorical variables were given as percentages. Unpaired Student's t-tests were used to compare continuous data, Pearson's $\chi^{2}$ and Fisher's exact tests were used for categorical variables. Univariate analysis was performed on selected variables. Significant variables $(p<0.30)$ were entered the Cox multivariable logistic regression with morbidity as the dependent variable. Spearman's rank correlation coefficient was applied as needed. The significance was set at the 0.05 level. $\mathrm{R}$ was used for statistical analyses [15].

\section{Results}

On 31st October 2016, 3,851 patients were available in the Registry; ten institutions (each with $>100$ VATS lobectomies enrolled) contributed for a total of 1679 patients. Fig. 1 showed an anonymous overview of the contribution per centre; the median contribution was 162 patients (range: 100-293 patients). Table 1 reported the patients' demographics and characteristics, performed procedures, histology and pathological stages. Mean age was $67.3 \pm 10.4$ years, and the male/female ratio was 1.5 (male $=59.7 \%$ ). The indication for VATS lobectomies was predominantly oncological (primary lung cancer $=92.9 \%$, metastatic lung cancer $=4.1 \%$ ). $96.1 \%$ of patients were naïve to preoperative oncological treatments. The left/right side ratio was $62.2 \%$. The surgical procedures performed were right upper lobectomy (36.2\%), left upper lobectomy (21.9\%), right lower lobectomy (17.3\%), left lower lobectomy (16.5\%), right middle lobectomy (7.2\%), and bilobectomy (lower $=0.7 \%$, upper $=0.4 \%$ ). Adenocarcinoma was the more common histology (64.6\%). Postoperative histology confirms that VATS lobectomy was prevalently performed in early-stage lung cancer (79.1\%). The overall VATS experience ratio of centres was $44.2 \pm 20.0 \%$ (range: $24.3-64.2 \%$ ). Conversion to unplanned thoracotomy due to vascular injuries was observed in 44 (2.6\%) of patients (Table 2). There was no significant variability of vascular accidents between centres. The incidence was $1.5 \%(25 / 1,679)$ on the right side, and $1.1 \%(19 / 1,679)$ on the left side, with a left/right ratio of $76.0 \%$. More than $60 \%$ of the vascular injuries occurred during upper lobectomies (left upper lobectomy $=31.5 \%$, right upper lobectomy $=29.6 \%$ ). The other stratified incidences of vascular injuries were reported in Table 2. Vascular injuries occurred more frequently in patients with tumour diameter $<3 \mathrm{~cm}(68.2 \%)$. There were no statistically significant differences in the occurrence of vascular accidents and the adopted surgical techniques. Only one patient $(2.3 \%)$ has received induction chemotherapy before VATS lobectomy. The intraoperative median blood loss was $780 \mathrm{~mL}$ (range: $217-1,429 \mathrm{~mL}$ ). The operative median time (skin-to-skin) was $<5 \mathrm{~h}$ ( 140 minutes, range: $122-250$ minutes). The median hospital length of stay was 9 days (range: 5-38 days). There was not a statistical trend $(\rho=0.10)$ of higher conversion rate (due to vascular injuries) during the first half of the patients recorded in the database. The overall conversion rate was significantly unrelated $(\rho=-0.54)$ to the years of experiences of the surgeons involved. Intraoperative mortality was absent. Overall morbidity occurred in 4 (9.1\%) patients: atrial fibrillation in 2 (4.5\%), postoperative air leak in 1 (2.3\%), redo thoracotomy for bleeding in 1 (2.3\%).

Univariate analysis showed age, gender, the surgical activity of centre, Charlson Index Score, the number of resected lymph nodes, overall postoperative complications, and VATS experience ratio as significant variables (Table 3). The multivariate analysis revealed that only number of resected lymph nodes $(\mathrm{OR}=2.64,95 \% \mathrm{CI}$ : $1.11-3.28, \mathrm{p}=0.041)$, the VATS experience ratio $(\mathrm{OR}=1.56,95 \% \mathrm{CI}$ : 


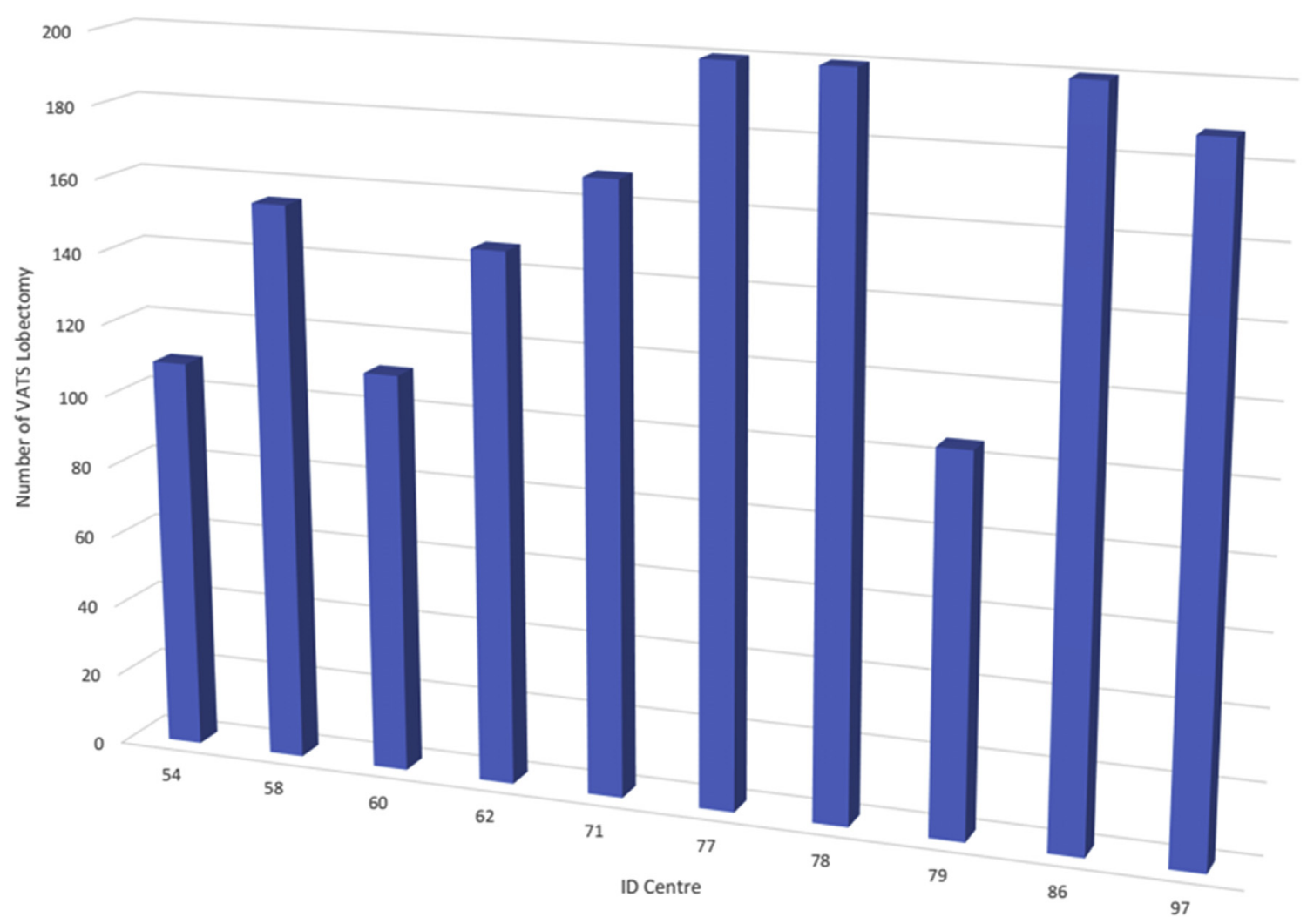

Fig. 1. Contribution of VATS lobectomies per centre.

Table 1

Patients' demographics and characteristics, performed procedure, histological and pathological stage (if applicable). Data are expressed as number (percentage), if not otherwise defined. * Data available for 1,581 patients. ${ }^{* *}$ Data available for 1,628 patients. SD = standard deviation.

\begin{tabular}{|c|c|c|}
\hline Variable & & No. (\%) \\
\hline \multirow[t]{2}{*}{ Gender } & Male & $1,003(59.7)$ \\
\hline & Female & $676(40.3)$ \\
\hline Age $($ mean $\pm S D)$ & $67.3 \pm 10.4$ years & \\
\hline \multirow[t]{3}{*}{ Preoperative indication } & Primary & $1,560(92.9)$ \\
\hline & Metastasis & $68(4.1)$ \\
\hline & Benign & $51(3.0)$ \\
\hline \multirow{3}{*}{$\begin{array}{l}\text { Previous chemotherapy } \\
\text { or radiotherapy }\end{array}$} & None & $1,614(96.1)$ \\
\hline & Chemotherapy & $57(3.4)$ \\
\hline & Radiotherapy & $8(0.5)$ \\
\hline \multirow[t]{2}{*}{ Side } & Left & $644(38.4)$ \\
\hline & Right & $1,035(61.4)$ \\
\hline \multirow[t]{7}{*}{ Stratified procedure } & Left upper lobectomy & $367(21.9)$ \\
\hline & Left lower lobectomy & $277(16.5)$ \\
\hline & Right upper lobectomy & $607(36.2)$ \\
\hline & Right middle lobectomy & $120(7.2)$ \\
\hline & Right lower lobectomy & $290(17.3)$ \\
\hline & Upper Bilobectomy & $6(0.4)$ \\
\hline & Lower Bilobectomy & $12(0.7)$ \\
\hline \multirow[t]{6}{*}{ Definitive histology * } & Adenocarcinoma & $1,084(64.6)$ \\
\hline & Squamous cell carcinoma & $265(15.8)$ \\
\hline & Typical carcinoid & $83(5.2)$ \\
\hline & Atypical carcinoid & 30 (1.9) \\
\hline & Metastasis & $68(4.3)$ \\
\hline & Other & $51(3.0)$ \\
\hline \multirow[t]{7}{*}{ pTNM stage (VII edition) ${ }^{* *}$} & IA & $949(58.3)$ \\
\hline & IB & $338(20.8)$ \\
\hline & IIA & $150(9.2)$ \\
\hline & IIB & $51(3.1)$ \\
\hline & IIIA & $128(7.8)$ \\
\hline & IIIB & $3(0.2)$ \\
\hline & IV & $9(0.6)$ \\
\hline
\end{tabular}

Table 2

Surgical details of the patients underwent unplanned thoracotomy due to a vascular injury. Data expressed as number (percentage), if not otherwise defined. SD = Standard Deviation.

\begin{tabular}{|c|c|c|}
\hline Variable & & No. (\%) \\
\hline \multirow[t]{2}{*}{ Side } & Left & $\begin{array}{l}19 \\
(43.2)\end{array}$ \\
\hline & Right & $\begin{array}{l}25 \\
(56.8)\end{array}$ \\
\hline \multirow[t]{7}{*}{ Stratified procedure } & Left upper lobectomy & $\begin{array}{l}14 \\
(31.8)\end{array}$ \\
\hline & Left lower lobectomy & $5(11.4)$ \\
\hline & Right upper lobectomy & $\begin{array}{l}13 \\
(29.6)\end{array}$ \\
\hline & Right middle & $3(6.8)$ \\
\hline & lobectomy & \\
\hline & Right lower lobectomy & $8(18.2)$ \\
\hline & Lower Bilobectomy & $1(2.3)$ \\
\hline \multirow[t]{4}{*}{ Tumour diameter } & $<2 \mathrm{~cm}$ & $\begin{array}{l}19 \\
(43.2)\end{array}$ \\
\hline & $2-3 \mathrm{~cm}$ & $\begin{array}{l}11 \\
(25.0)\end{array}$ \\
\hline & $3-5 \mathrm{~cm}$ & $9(20.5)$ \\
\hline & $5-7 \mathrm{~cm}$ & $5(11.4)$ \\
\hline \multirow[t]{4}{*}{ Number of Incisions } & 1 & $4(9.1)$ \\
\hline & 2 & $7(15.9)$ \\
\hline & 3 & $\begin{array}{l}27 \\
(61.4)\end{array}$ \\
\hline & $>3$ & $6(13.6)$ \\
\hline Previous chemotherapy or radiotherapy & Chemotherapy & $1(2.3)$ \\
\hline Blood Loss (median (range)) & $780(217-1429) \mathrm{mL}$ & \\
\hline Operative Time (median (range)) & 140 (122-250) minute & \\
\hline \multirow[t]{4}{*}{ Postoperative morbidity } & Overall & $4(9.1)$ \\
\hline & - Atrial fibrillation & $2(4.5)$ \\
\hline & $\begin{array}{l}\text { - Postoperative air } \\
\text { leaks }\end{array}$ & $1(2.3)$ \\
\hline & - Redo thoracotomy & $1(2.3)$ \\
\hline $\begin{array}{l}\text { Postoperative Length of Hospital Stay } \\
\text { (Median) }\end{array}$ & 9 days (range: $5-38 \mathrm{da}$ & ays) \\
\hline
\end{tabular}


Table 3

Univariate and Cox multivariable logistic regression analysis. $\mathrm{CI}=$ confidence interval; OR = Odds ratio; VATS Experience Ratio = number of VATS anatomical resections on total anatomical resections (performed in the same year at same centre).

\begin{tabular}{llllll}
\hline \multirow{2}{*}{ Variable } & Univariate & & \multicolumn{2}{l}{ Multivariate } & \\
\cline { 2 - 2 } \cline { 5 - 6 } \cline { 5 - 6 } & p-value & & OR & $95 \% \mathrm{CI}$ & p-value \\
\hline Age & 0.042 & & 1.01 & $0.98-1.06$ & 0.18 \\
Gender & 0.25 & & 0.94 & $0.86-1.80$ & 0.16 \\
ECOG score & 0.88 & & & & \\
Previous surgery & 0.81 & & & & \\
Previous chemotherapy & 0.32 & & & & \\
Previous radiotherapy & 0.78 & & & & \\
Side & 0.51 & & & & \\
Charlson Index & 0.10 & & 1.48 & $0.71-3-11$ & 0.34 \\
Number of incisions & 0.49 & & & & \\
Number of resected lymph nodes & 0.15 & & 2.64 & $1.11-3.28$ & 0.041 \\
Overall postoperative complication & 0.11 & & 1.07 & $0.91-1.36$ & 0.054 \\
Hospital length of stay & 0.76 & & & & \\
Surgical activity of centre & 0.10 & & 0.97 & $0.94-0.99$ & 0.021 \\
VATS Experience Ratio & 0.13 & & 1.56 & $1.21-2.43$ & 0.043 \\
\hline
\end{tabular}

1.21-2.43, $\mathrm{p}=0.043)$, and the surgical activity of the centre ( $\mathrm{OR}=0.97,95 \% \mathrm{CI}: 0.94-0.99, \mathrm{p}=0.021)$ were associated as risk factors of conversion due to a vascular injury (Table 3). Also, unplanned thoracotomy was strongly correlated $(\rho=0.68)$ with increase in overall postoperative morbidity.

\section{Discussion}

Despite pulmonary artery bleeding is considered among the most feared situations during hilar VATS dissection, the related risk factors and the direct consequences of these vascular injuries are challenging to study, and this issue is not widely covered in the medical literature in comparison to other comparable topics regarding minimally invasive techniques. Incidence of vascular damages reported by large volume centres and by skilled surgeons is slight [16], and reports of intra-operative catastrophes, including death, caused by uncontrolled bleeding in high-volume centres are also negligible. However, the incidence of vascular injuries across the spectrum of surgical experience is likely to be higher. In fact, occurrence of vascular incidents (or complications that result from vascular injuries during VATS lobectomy) is possible underreported: it can be difficult to track in the administrative databases, as converted cases may be coded merely as "intentional thoracotomy approach" (generally without any mention of the emergency conversion due to the injury) or they only cannot be captured if the lesion has been successfully managed thoracoscopically [17].

Berry et al. reported a range of unplanned thoracotomy due to bleeding from $0.5 \%$ to $5.2 \%$ [17], Mei et al. a $4.1 \%$ of vascular injury rate [18], and Kawachi et al. described an 8.2\% [19]. Yano et al. focused on the impact of adverse events related to pulmonary vascular stapling in thoracic surgery (not only by VATS) discovered as high as $0.27 \%$ [20]. It might be noted otherwise that while most of the vascular injuries are related to a challenging and hazardous vessel dissection, stapler failure is only anecdotic, and most of the stapler malfunctions could be related to human mistakes in handling and appropriately manipulating vessels [21]. Decaluwe et al. analysed the vascular injuries among a vast population coming from the European Society of Thoracic Surgeons (ESTS) database and found an incidence of 2.9\% [13].

In the VATS Registry, the vascular injuries were reported in $2.27 \%$ patients and more frequently occurred during upper lobectomies (left $>$ right), regardless the VATS technique employed (Copenhagen triportal approach, biportal approach, uniportal approach, etc.). Interestingly $>75 \%$ of the conversions were for small-size early-stage lung cancers ( $43 \%$ for tumours $<2 \mathrm{~cm}$ and $25 \%$ for tumours between 2 and $3 \mathrm{~cm}$ in maximum diameter). In the multivariate analysis, three variables were identified as statistically significant: the volume of surgical activity of centre, the VATS experience ratio and the number of lymph nodes harvested during dissection. All correlated with the risk of vascular injury and that should be regarded not only as a stochastic event.

The literature evidence is not homogeneous, and the comparison of different surgical approaches is difficult. Many factors, whose influence cannot be evinced with logistic regression analyses, could cause a vascular injury. In our data, the number of resected lymph nodes was an independent risk factor for conversion: it could be argued that as higher the number of lymph nodes harvested more demanding the vascular dissection, therefore, an increased risk of vascular injuries. It is well accepted that hilar adhesions due to lymphadenopathy are responsible for most of the vascular injuries requiring an unplanned thoracotomy [18,22-24] and that skilled surgeons could move beyond the boundaries to a more aggressive lymph nodes dissection [22]. Unfortunately only a minority of potential conversion due complicated hilar preparation are predictable preoperatively: for example, the conversion could be expected in case of extensive hilar nodal calcifications or vascular anomalies evident on preoperative chest computed tomography (CT) [1].

The relatively elevated median blood loss and the long median postoperative length of stay of could reflect a relatively excess of postoperative complications. In addition, the volume of bleeding could reflect the intraoperative complications managed without conversions. Nonetheless, the primary concerns with unplanned thoracotomy for vascular injuries are the possible increased risk of morbidity and mortality. In fact, patients who underwent sudden thoracotomy conversion most likely experience a longer operating time, further lung manipulation, an increased risk of damage to adjacent tissues including the risk of a "salvage pneumonectomy" and an increased blood loss, which may all adversely affect the outcome. Although the safety of uncomplicated VATS lobectomy is widely documented, there are fewer data regarding short- and long-term outcomes of failed VATS lobectomy.

In Registry, no intra-operative deaths occurred among these patients, possibly due to a proper timing of conversion due to the seniority of the surgeons; nevertheless, unplanned thoracotomy correlated with postoperative morbidity. Our current intraoperative management for bleeding from a significant pulmonary arterial branch injury referred to the Cerfolio's rule of the four " $P$ ": Poise; Pressure to apply immediately to the bleeding vessel; Preoperatively preparedness of a disaster plan (not rush preparation of thoracotomy after the injury); Proximal control of the vessel bleeding [25]. Augustin et al. [27] confirmed that conversion during VATS lobectomy did not negatively affect the short-term outcome and, therefore, should not be considered a failure. Patient safety must remain the primary focus and conversion should be discussed at any time when patient safety is not guaranteed. Conversion should be considered more a resource to preserve patient's safety rather than the failure of the VATS approach. Therefore, the correct assessment of any bleeding is of paramount importance during every VATS procedure [26]. Delayed conversion and an unsuccessful attempt to manage complications with minimally invasive techniques increase the risk of unfortunate intraoperative events [27].

VATS experience was proportionally inverted to the conversion rates due to technical reasons. Nevertheless, the proportions of patients converted owing to vascular bleeding remained independent to the seniority. While surgeons can quickly learn to foresee a variety of technical challenges, conversion rates should not be related only to the learning curve and not expected to decrease 
below a certain proportion [24]. Decaluwe et al. reported the VATS experience ratio significantly higher in patients with significant bleeding, supporting that the risk of vascular injury increases with the surgeons' seniority [13]. Nevertheless, other authors showed that major complications occurred in every point of the learning curve and not describe the relationship between seniority and adverse events $[3,28]$. In VATS Group data set, comparing the time series of the consecutive cases, a statistical trend was not seen for a higher conversion rate in the first half, indicating a reduced impact of the learning curve on conversion. There are several explanations for this finding likewise the absence of patients' selection and the stochastic characteristics of the database. The stable conversion rate also marks the learning curve of surgeons who work in high volume centres [27]. It was also suggested that the comparison group for morbidity of unplanned converted procedures should comprise those undergoing a planned thoracotomy. Nevertheless, previous literature has not demonstrated a difference in postoperative outcomes between these patient groups [24].

\section{Limitations}

Our study has several limitations. The analysis was limited by its retrospective design, with selection criteria for VATS lobectomy and decision for conversion not homogeneously assigned by the centres, potentially resulting in classification bias. Although the present study is focused on the activity of ten high-volume selected centres in Italy, as already shown for other more substantial databases revisions, the selection standards may differ between centres [29]. Some additional surgery specific parameters (the VATS experience ratio, the surgical volume, and the seniority) were adopted to minimise these biases.

Unfortunately, the details on the exact mechanism of vascular injuries and its definitive management are not coded in the database; to accurately identify these complications, an intention-totreat field will be added in the next web version, inclusive of the details of the planned surgical procedure. Although in our series 44 patients had an unplanned conversion due to vascular damage, the incidence of other vascular injuries successfully managed thoracoscopically without conversion could not be explored in this patient cohort. The absence of this information might reflect in an under-estimation of the cumulative numbers of injuries (missing denominator). Also, the timing of vascular injury has not been reported. The exact time of conversion could provide an insight into the intraoperative decision making and factors affecting the prompt anticipation of potential difficulties.

The statistical comparison of the results between unplanned conversions and successful VATS lobectomies was not sufficiently powered due to the limited number of conversions. However, a prospectively designed or case-controlled study would be challenging to accomplish considering the low enrollment rate and the possibility of bias resulting from the infrequency of the condition.

Lastly, the follow-up period was relatively short if compared to previous studies [30] and also data regarding cancer recurrences and overall survival were not shown, but again were comparable to the previous series [30] and are behind the aim of the present manuscript.

In conclusion, vascular injuries during VATS lobectomies represent a rare complication but directly affect the postoperative outcome and are possibly not only a stochastic event. Multiple variables are involved if should be regarded as multi-factorial in its nature. In our analysis, the predictive factors for conversion were depending on characteristics of the centre (surgical activity and VATS experience ratio) and on the surgeons' seniority (number of excised lymph nodes as an expression of aggressiveness in performing the nodal dissection). Interestingly the minimally invasive approach (Copenhagen triportal, biportal, uniportal, etc.) did not influence the risk of vascular damages that were more frequent during upper lobectomies and in dealing with small size tumours $(<3 \mathrm{~cm})$.

\section{Conflict of interest}

None declared.

\section{References}

[1] Hanna JM, Berry MF, D'Amico TA. Contraindications of video-assisted thoracoscopic surgical lobectomy and determinants of conversion to open. J Thorac Dis 2013;5(Suppl 3):S182-9.

[2] Jawitz OK, Wang Z, Boffa DJ, Detterbeck FC, Blasberg JD, Kim AW. The differential impact of preoperative comorbidity on perioperative outcomes following thoracoscopic and open lobectomies. Eur J Cardiothorac Surg 2016;51:169-74

[3] Flores RM, Ihekweazu U, Dycoco J, Rizk NP, Rusch VW, Bains MS, et al. Videoassisted thoracoscopic surgery (VATS) lobectomy: catastrophic intraoperative complications. J Thorac Cardiovasc Surg 2011;142:1412-7.

[4] Vats Group. http://vatsgroup.org/sito/index.php (27/08/2017 date last accessed).

[5] De Leyn P, Dooms C, Kuzdzal J, Lardinois D, Passlick B, Rami-Porta R, et al. Revised ESTS guidelines for preoperative mediastinal lymph node staging for non-small-cell lung cancer. Eur J Cardiothorac Surg 2014;45:787-98.

[6] Rocco G, Internullo E, Cassivi SD, Van Raemdonck D, Ferguson MK. The variability of practice in minimally invasive thoracic surgery for pulmonary resections. Thorac Surg Clin 2008:18:235-47.

[7] Petersen RH, Hansen HJ. Learning curve associated with VATS lobectomy. Ann Cardiothorac Surg 2012;1:47-50.

[8] Bedetti B, Bertolaccini L, Solli P, Scarci M. Learning curve and established phase for uniportal VATS lobectomies: the Papworth experience. J Thorac Dis 2017;9:138-42.

[9] Brunelli A, Falcoz PE, D'Amico T, Hansen H, Lim E, Massard G, et al. European guidelines on structure and qualification of general thoracic surgery. Eur J Cardiothorac Surg 2014;45:779-86.

[10] Charlson ME, Pompei P, Ales KL, MacKenzie CR. A new method of classifying prognostic comorbidity in longitudinal studies: development and validation. J Chron Dis 1987:40:373-83.

[11] Oken MM, Creech RH, Tormey DC, Horton J, Davis TE, McFadden ET, et al. Toxicity and response criteria of the eastern cooperative Oncology group. Am J Clin Oncol 1982;5:649-55.

[12] Goldstraw P. The 7th edition of TNM in lung cancer: what now? J Thorac Oncol 2009;4:671-3.

[13] Decaluwe H, Petersen RH, Hansen H, Piwkowski C, Augustin F, Brunelli A, et al. Major intraoperative complications during video-assisted thoracoscopic anatomical lung resections: an intention-to-treat analysis. Eur J Cardiothorac Surg 2015;48:588-98. discussion 99.

[14] Dixon JR. The international conference on harmonization Good clinical practice guideline. Qual Assur 1999;6:65-74.

[15] R Development Core Team. R: a language and environment for statistical computing. Vienna, Austria: R Foundation for Statistical Computing; 2010.

[16] Fernandez Prado R, Fieira Costa E, Delgado Roel M, Fernandez LM, Paradela de la Morena M, de la Torre M, et al. Management of complications by uniportal video-assisted thoracoscopic surgery. J Thorac Dis 2014;6:S669-73.

[17] Berry MF. Pulmonary artery bleeding during video-assisted thoracoscopic surgery. Thorac Surg Clin 2015;25:239-47.

[18] Mei J, Pu Q, Liao H, Ma L, Zhu Y, Liu L. A novel method for troubleshooting vascular injury during anatomic thoracoscopic pulmonary resection without conversion to thoracotomy. Surg Endosc 2013:27:530-7.

[19] Kawachi R, Tsukada H, Nakazato Y, Takei H, Koshi-ishi Y, Goya T. Morbidity in video-assisted thoracoscopic lobectomy for clinical stage I non-small cell lung cancer: is VATS lobectomy really safe? Thorac Cardiovasc Surg 2009;57: $156-9$

[20] Yano M, Takao M, Fujinaga T, Arimura T, Fukai I, Ota S, et al. Adverse events of pulmonary vascular stapling in thoracic surgery. Interact Cardiovasc Thorac Surg 2013;17:280-4.

[21] Miyazaki T, Yamasaki N, Tsuchiya T, Matsumoto K, Hatachi G, Kitamura Y, et al. Management of unexpected intraoperative bleeding during thoracoscopic pulmonary resection: a single institutional experience. Surg Today 2016;46:901-7.

[22] Sawada S, Komori E, Yamashita M. Evaluation of video-assisted thoracoscopic surgery lobectomy requiring emergency conversion to thoracotomy. Eur J Cardiothorac Surg 2009:36:487-90.

[23] Samson P, Guitron J, Reed MF, Hanseman DJ, Starnes SL. Predictors of conversion to thoracotomy for video-assisted thoracoscopic lobectomy: a retrospective analysis and the influence of computed tomography-based calcification assessment. J Thorac Cardiovasc Surg 2013;145:1512-8.

[24] Vallance A, Tcherveniakov P, Bogdan C, Chaudhuri N, Milton R, Kefaloyannis E. The evolution of intraoperative conversion in video assisted thoracoscopic 
lobectomy. Ann R Coll Surg Engl 2017;99:129-33.

[25] Cerfolio RJ, Bess KM, Wei B, Minnich DJ. Incidence, results, and our current intraoperative technique to control major vascular injuries during minimally invasive robotic thoracic surgery. Ann Thorac Surg 2016;102:394-9.

[26] Gonzalez-Rivas D, Stupnik T, Fernandez R, de la Torre M, Velasco C, Yang Y, et al. Intraoperative bleeding control by uniportal video-assisted thoracoscopic surgery. Eur J Cardiothorac Surg 2016;49(Suppl 1). i17-24.

[27] Augustin F, Maier HT, Weissenbacher A, Ng C, Lucciarini P, Öfner D, et al. Causes, predictors and consequences of conversion from VATS to open lung lobectomy. Surg Endosc 2015;30:2415-21.

[28] Fournel L, Zaimi R, Grigoroiu M, Stern JB, Gossot D. Totally thoracoscopic major pulmonary resections: an analysis of perioperative complications. Ann Thorac Surg 2014;97:419-24.

[29] Brunelli A, Salati M, Rocco G, Varela G, Van Raemdonck D, Decaluwe H, et al. European risk models for morbidity (EuroLung1) and mortality (EuroLung2) to predict outcome following anatomic lung resections: an analysis from the European Society of Thoracic Surgeons databasedagger,double dagger. Eur ] Cardiothorac Surg 2017;51:490-7.

[30] Park JS, Kim HK, Choi YS, Kim J, Shim YM, Kim K. Unplanned conversion to thoracotomy during video-assisted thoracic surgery lobectomy does not compromise the surgical outcome. World J Surg 2011;35:590-5. 